\title{
Nanofluid Flow Past a Stretching Plate
}

\author{
Gabriella Bognár ${ }^{1, * \mathbb{D}}$, Mohamad Klazly ${ }^{1}$ and Krisztián Hriczó ${ }^{2} \mathbb{D}$ \\ 1 Institute of Machine and Product Design, University of Miskolc, 3515 Miskolc-Egyetemváros, Hungary; \\ eng.klazly@gmail.com \\ 2 Institute of Mathematics, University of Miskolc, 3515 Miskolc-Egyetemváros, Hungary; \\ mathk@uni-miskolc.hu \\ * Correspondence: v.bognar.gabriella@uni-miskolc.hu
}

Received: 31 May 2020; Accepted: 10 July 2020; Published: 13 July 2020

check for updates

\begin{abstract}
Viscous nanofluid flow due to a sheet moving with constant speed in an otherwise quiescent medium is studied for three types of nanofluids, such as alumina $\left(\mathrm{Al}_{2} \mathrm{O}_{3}\right)$, titania $\left(\mathrm{TiO}_{2}\right)$, and magnetite $\left(\mathrm{Fe}_{3} \mathrm{O}_{4}\right)$, in a base fluid of water. The heat and mass transfer characteristics are investigated theoretically using the boundary layer theory and numerically with computational fluid dynamics (CFD) simulation. The velocity, temperature, skin friction coefficient, and local Nusselt number are determined. The obtained results are in good agreement with known results from the literature. It is found that the obtained results for skin friction and for the Nusselt number are slightly greater than those obtained via boundary layer theory.
\end{abstract}

Keywords: Sakiadis flow; moving surface; nanofluid; CFD; similarity method; skin friction; Nusselt number

\section{Introduction}

The development of boundary layer theory was initiated by Ludwig Prandtl [1] in the early 1900s, and many world-renowned scientists, including Blasius [2], have worked on further development. The name of the boundary layer comes from Prandtl, and in this layer we find a significant change in velocity, such as a layer close to the surface of a solid body. However, there is another type of boundary layer, and in addition to the change in velocity, a thermal boundary layer can also be defined based on the change in temperature. Prandtl's theory led to the conclusion that the losses of fluid flowing in a pipe or duct occur almost entirely in the usually very thin boundary layer adhering to the wall. The analytical solution to the boundary layer problem comes from Blasius introducing the similarity method [3].

Prandtl's boundary layer theory is applied to many practical engineering problems to predict skin friction drag. In metallurgical, petrochemical, and plastics processing applications, boundary layer theory is very important. The surface-driven flow in a resting fluid plays an important role in many material processing processes, e.g., hot rolling, metalworking, and continuous casting (see [4-6]). The flow of the boundary layer of a plane moving at a uniform velocity in Newtonian fluid was investigated analytically by Sakiadis [7]. His results were experimentally verified by Tsou et al. [8]. The continuous extrusion of polymer sheets from a die to the winding cylinder was investigated. The slit and the winding cylinder are placed at a finite distance from each other. Sakiadis assumed that a steady state would develop after a certain time after the start of the process. Tsou et al. [8] showed in their studies containing both analytical and experimental results that the laminar velocity field determined with the analytical solution for Newtonian fluid show a very good agreement with the measured data.

The Sakiadis problem of fluid flow along sheet surfaces has been extended in many ways in recent decades. In the case of linear stretching, Crane [9] provided a solution to Sakiadis' problem 
for heat and mass transfer in a closed form with exponential function. Chakrabarti and Gupta investigated flow characteristics over a linearly stretched surface through a transverse magnetic field [10]. When the surface is stretched nonlinearly, Banks investigated the governing boundary layer equations [11]. The flow characteristics of non-Newtonian power law-type fluids over a stretched sheet was investigated by Bognár et al. [12-14]. Haider et al. [15] analysed magnetohydrodynamic viscous fluid flow due to exponentially stretching sheet with the homotopy analysis method. In [16], Mahabaleshwar examines the flow properties of fluid flow through porous media for a variety of boundary conditions. Among the different rheological models, the Walters-B fluid model is applied for description of the complex flow behaviour of various polymer solutions. Andersson investigated the Walters-B flow characteristics along a linearly stretching surface [17]. In [18], Walters-B Sakiadis boundary layer flow is solved by Tonekaboni et al. An incompressible and electrically conducting isothermal viscoelastic Walters-B fluid flow due to a stretching surface with quadratic velocity was studied by Siddheshwar [19]. The boundary layer equations through a porous medium over a stretching plate with superlinear stretching velocity were investigated by Singh et al. [20]. The influence of variable viscosity is analysed in heat and mass transfer properties in [21-24].

Recently, in the literature, the nanofluid flows have been of great interest. Nanofluids are smart solutions in heat exchangers applied in many industrial applications responsible for the transfer of heat between fluids and device surfaces. Their applications include air conditioning systems, nuclear reactors, solar film collectors, etc.First, Choi [25] introduced the term of nanofluids. The purpose of adding nano-sized solid particles to the base fluid, e.g., metals, metal oxides, and ceramics, is to enhance thermal the conductivity of base fluids. It is known that by combining a very small number of nanoparticles to traditional base fluids, the thermal conductivity can be increased up to two times [26-28]. Mathematical modelling of nanofluids is integrated as single-phase model or a two-phase model into the description of the flow, for the governing equations.Raza et al. [29] investigated the effect of temperature-dependent thermal conductivity on Williamson nanofluid flow in a nonlinearly stretching, variable-thickness plate in the presence of magnetic field. The magnetohydrodynamic stagnation point flow for nanofluids past a stretching surface with melting heat transfer was studied by Ibrahim [30].

Ahmad et al. [31] and Bachok et al. [32] tested the effect of solid nanoparticle concentration for the Blasius and Sakiadis problems by investigating $\mathrm{Cu}, \mathrm{Al}_{2} \mathrm{O}_{3}$, and $\mathrm{TiO}_{2}$. Gingold [33] pointed out that due to the simplifications applied in boundary layer theory, we only get approximate values for flow characteristics. Experimental results published by Liepmann [34] and Schlichting [3] for fluid flow over a flat surface showed lower velocity values in the neighbourhood of the surface compared to the solution obtained using the boundary layer theory. The experiments of Janour [35], Schaaf, and Sherman [36] resulted in a higher skin friction drag in the range 0-1000 of the Reynolds number than in the theoretical Blasius solution.

The researchers have found that microfluidic flow could be used to grow defect-free crystals, as demonstrated in the papers [37,38]. Recently, several authors have shown their keen interest in the heat and mass transfer phenomena of nanofluid flow over stretching sheet (see [39-43]).

Following the investigations in [31,32], our aim is to present an analysis for the flow and heat transfer characteristics of a continuously moving flat plate in a nanofluid. The problem is solved using computational fluid dynamics (CFD), as well as analytically with the similarity approach, for three types of nanofluids of nanoparticles, namely alumina $\left(\mathrm{Al}_{2} \mathrm{O}_{3}\right)$, titania $\left(\mathrm{TiO}_{2}\right)$, and magnetite $\left(\mathrm{Fe}_{3} \mathrm{O}_{4}\right)$, with water as the base fluid. The main interest is to show the influence of the concentration on the fluid characteristics, and to compare the velocity and temperature distribution, the skin friction, and Nusselt number obtained with the two solution techniques.

\section{Mathematical Formulation}

Consider a two-dimensional laminar boundary layer flow over a continuously moving, flat surface for a water-based nanofluid containing three different types of nanoparticles. The thermophysical 
properties of the nanofluids are given in Table 1 [44]. The shape of the nanoparticles is spherical, and the average particle size is considered to be $20 \mathrm{~nm}$. It is assumed that the nanofluid is incompressible, the flow is laminar, and the effect of viscous distribution and radiation is negligible.

Table 1. The thermophysical properties of water, as well as $\mathrm{Al}_{2} \mathrm{O}_{3}, \mathrm{TiO}_{2}$, and $\mathrm{Fe}_{3} \mathrm{O}_{4}$ particles.

\begin{tabular}{ccccc}
\hline Parameter & $\mathbf{F e}_{3} \mathbf{O}_{\mathbf{4}}$ & $\mathrm{TiO}_{\mathbf{2}}$ & $\mathbf{A l}_{\mathbf{2}} \mathbf{O}_{\mathbf{3}}$ & $\mathbf{H}_{\mathbf{2}} \mathbf{O}$ \\
\hline$\rho\left(\mathrm{kg} / \mathrm{m}^{3}\right)$ & 5180 & 4250 & 3970 & 997.1 \\
$C_{p}(\mathrm{~J} / \mathrm{kg} \cdot \mathrm{K})$ & 670 & 686.2 & 765 & 4179 \\
$k(\mathrm{~W} / \mathrm{m} \cdot \mathrm{K})$ & 9.7 & 8.9538 & 40 & 0.613 \\
$\mu(\mathrm{Pa} \cdot \mathrm{s})$ & - & - & - & 0.001 \\
\hline
\end{tabular}

In the Cartesian coordinate system, the $x$-axis is chosen along the flow direction, while the $y$-axis is perpendicular to the surface. The nanofluid is confined above the horizontal surface, which coincides with the positive $x$-axis. The ambient fluid has a constant temperature $T_{\infty}$, and the temperature of the surface is $T_{w}$. In our case $T_{w}<T_{\infty}$. The velocity components $u$ and $v$ are the parallel and normal velocity components to the plate, respectively; $\mu_{n f}$ denotes the dynamic viscosity, $\rho_{n f}$ is the density, and $\alpha_{n f}$ is the thermal diffusivity of the nanofluid.

Using these assumptions and notations, the continuity, momentum, and energy equations in the vectoral form for the steady flow can be formulated as follows:

$$
\begin{gathered}
\nabla \cdot \vec{V}=0, \\
(\vec{V} . \nabla) \vec{V}=-\frac{1}{\rho_{n f}} \nabla p+\frac{\mu_{n f}}{\rho_{n f}} \nabla^{2} \vec{V}, \\
(\vec{V} \cdot \nabla) T=\alpha_{n f} \nabla^{2} T,
\end{gathered}
$$

where the following notations are used: $\vec{V}$ is the velocity vector, $T$ is the temperature of the nanofluid, and $p$ is the pressure of the nanofluid.

In the traditional boundary layer theory, many assumptions are made: the momentum and thermal boundary layer are very thin, compared with the flow's length scale, and grow in the direction of motion of the surface; the velocity parallel to the wall is much larger than the velocity components (v); and the derivatives of the velocity components to the wall are large [33]. The part of the liquid flow that is outside the thermal boundary layer is not affected by the heat transfer of the moving surface. Under these approximations, Equations (1)-(3) are written in the following forms:

$$
\begin{gathered}
\frac{\partial u}{\partial x}+\frac{\partial v}{\partial y}=0 \\
u \frac{\partial u}{\partial x}+v \frac{\partial u}{\partial y}=\frac{\mu_{n f}}{\rho_{n f}} \frac{\partial^{2} u}{\partial y^{2}} \\
u \frac{\partial T}{\partial x}+v \frac{\partial T}{\partial y}=\alpha_{n f} \frac{\partial^{2} T}{\partial y^{2}}
\end{gathered}
$$

The flow of nanofluid in an otherwise quiescent medium along a plate moving at a constant speed $U$ is examined. Conventional impermeability and anti-slip are applied to the solid surface, and in addition to the viscous boundary layer, the flow rate component $u=0$. The boundary conditions for the velocity and temperature fields for the Sakiadis flow problem are

$$
u(x, 0)=U, v(x, 0)=0, T(x, 0)=T_{w}, \lim _{y \rightarrow \infty} u(x, y)=0, \lim _{y \rightarrow \infty} T(x, y)=T_{\infty}
$$


For the thermophysical properties of the nanoparticle-water nanofluid, the following formulas are defined for the effective density:

$$
\rho_{n f}=(1-\phi) \rho_{b}+\phi \rho_{p}
$$

where $\rho_{b}$ and $\rho_{p}$ denote the density base fluid and nanoparticles, respectively, and $\phi$ denotes nanoparticle volume fraction; for the effective viscosity

$$
\mu_{n f}=\frac{\mu_{b}}{(1-\phi)^{2.5}}
$$

where $\mu_{n f}$ is the viscosity of the nanofluid and $\mu_{b}$ is the viscosity of the base fluid; for the effective heat capacity

$$
\left(\rho C_{p}\right)_{n f}=\phi\left(\rho C_{p}\right)_{p}+(1-\phi)\left(\rho C_{p}\right)_{b}
$$

and for the effective thermal conductivity

$$
k_{n f}=k_{b} \frac{k_{p}+2 k_{b}-2 \phi\left(k_{b}-k_{p}\right)}{k_{p}+2 k_{b}+\phi\left(k_{b}-k_{p}\right)}
$$

where $k_{n f}$ denotes the thermal conductivity of nanofluid, $k_{b}$ the thermal conductivity of base fluid, and $k_{p}$ the thermal conductivity of the particles.

The Sakiadis problem has been reported in the physical and mathematical literature, and this has again aroused interest in the analytical and numerical study of boundary layers. By analogy with the Sakiadis description, we studied the similarity solutions and the CFD simulation results to investigate the heat and mass properties, comparing the obtained results and giving numerical justification of the Blasius boundary layer approach.

\section{Results Using Similarity Method and Discussion}

Let us now introduce the stream function $\psi$ as

$$
u=\frac{\partial \psi}{\partial y}, v=-\frac{\partial \psi}{\partial x}
$$

Applying similarity transformations with the dimensionless similarity variable

$$
\eta=\left(\frac{U}{v_{n f} x}\right)^{\frac{1}{2}} y
$$

the stream function and the non-dimensional temperature are expressed as

$$
\psi=\left(U v_{n f} x\right)^{\frac{1}{2}} f(\eta), \theta(\eta)=\frac{T-T_{\infty}}{T_{w}-T_{\infty}}
$$

where $v_{n f}=\frac{\mu_{n f}}{\rho_{n f}}$ denotes the kinematic viscosity.

Taking the substitution (12), the continuity Equation (4) is automatically satisfied. The momentum Equation (5) and the thermal energy Equation (6) are transformed into a set of ordinary differential equations. From Equations (5) and (6), we obtain a system of ordinary differential equations for $f$ and $\theta$, as follows:

$$
\begin{gathered}
\frac{\rho_{b}}{\rho_{n f}} \frac{\mu_{n f}}{\mu_{b}} f^{\prime \prime \prime}+\frac{1}{2} f f^{\prime \prime}=0 \\
\alpha_{n f} \frac{\rho_{b}}{\mu_{b}} \theta^{\prime \prime}+\frac{1}{2} f \theta^{\prime}=0
\end{gathered}
$$


Where the prime denotes the differentiation with respect to $\eta$. Under conditions (7), these equations are considered together with the following boundary conditions:

$$
\begin{gathered}
f(0)=0, f^{\prime}(0)=1, \lim _{\eta \rightarrow \infty} f^{\prime}(\eta)=0, \\
\theta(0)=1, \lim _{\eta \rightarrow \infty} \theta(\eta)=0
\end{gathered}
$$

The dimensional velocity components can be given with the similarity function $f$ as

$$
\begin{gathered}
u(x, y)=U f^{\prime}(\eta) \\
v(x, y)=v^{*}(x)\left[\eta f^{\prime}(\eta)-f(\eta)\right]
\end{gathered}
$$

where $v^{*}(x)=\frac{1}{2} U \operatorname{Re}_{x}-\frac{1}{2}$, and the local Reynolds number $\operatorname{Re}_{x}$ is defined by $\operatorname{Re}_{x}=U x / v_{n f}$. The dimensional temperature is obtained as

$$
T(x, y)=T_{\infty}+\left(T_{w}-T_{\infty}\right) \theta(\eta)
$$

Using the fourth-order method (bvp4c) in MATLAB, the system (15) and (16) is solved with conditions (17) and (18), when the nanofluid properties are calculated according to formulas (8)-(11) using the thermophysical values given in Table 1 for $\mathrm{Al}_{2} \mathrm{O}_{3}, \mathrm{TiO}_{2}$, and $\mathrm{Fe}_{3} \mathrm{O}_{4}$ particles, as well as the base fluid of suspension water. Our aim was to investigate the impacts of the volume fraction and nanoparticle's material type on the heat and mass transfer characteristics.

Figure 1 exhibits the dimensionless velocity distributions for all three nanofluids for $2 \%$ additives in the base fluid. It shows that the velocity is greater for $\mathrm{Al}_{2} \mathrm{O}_{3}$ than for the other two materials. Figure 2 represents the temperature distribution for the same cases. Here, the $\mathrm{Al}_{2} \mathrm{O}_{3}$ also shows greater values than the others.

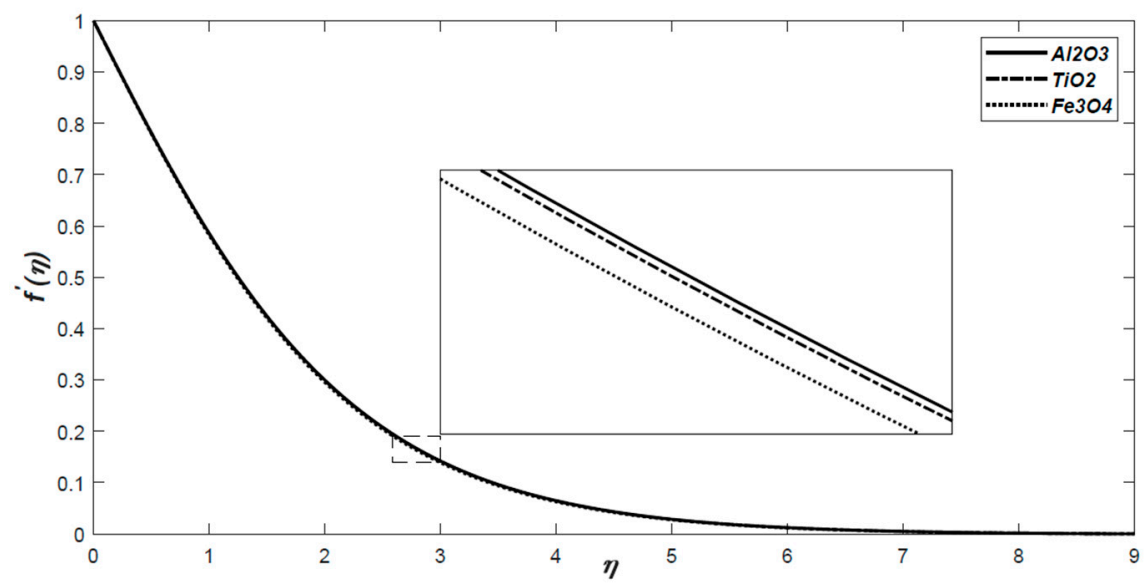

Figure 1. The dimensionless velocity profiles for volume fraction $\phi=0.02$ for all three nanofluids with respect to similarity variable $\eta$. 


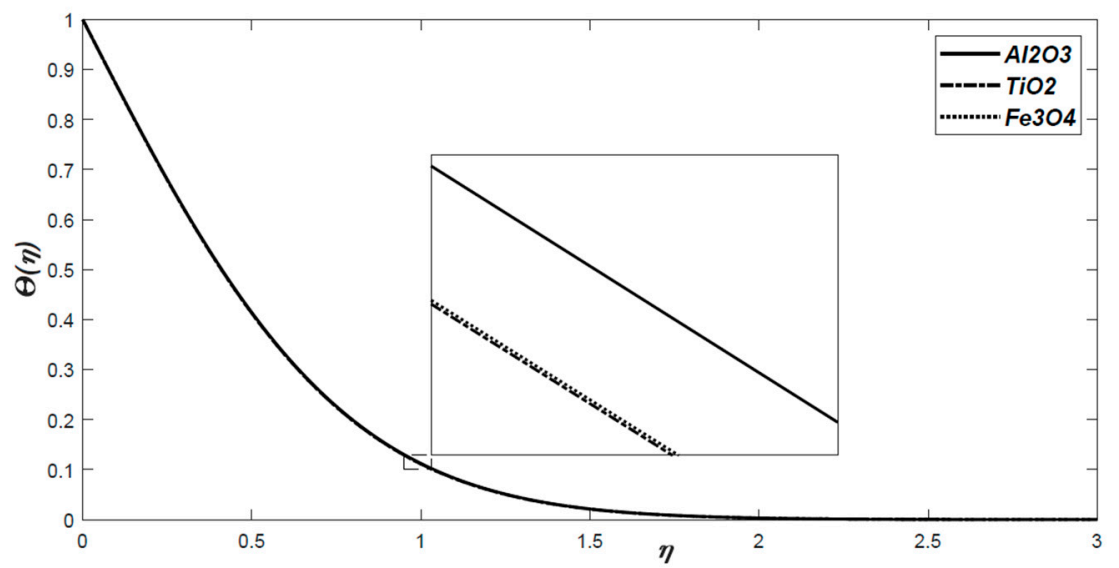

Figure 2. The dimensionless temperature profiles for $\phi=0.02$ for all three nanofluids with respect to similarity variable $\eta$.

The effect of the volume fraction $\phi$ is depicted in Figures 3 and 4 . It was observed that increasing $\phi$ will slow down the fluid flow velocity and will increase the non-dimensional temperature.

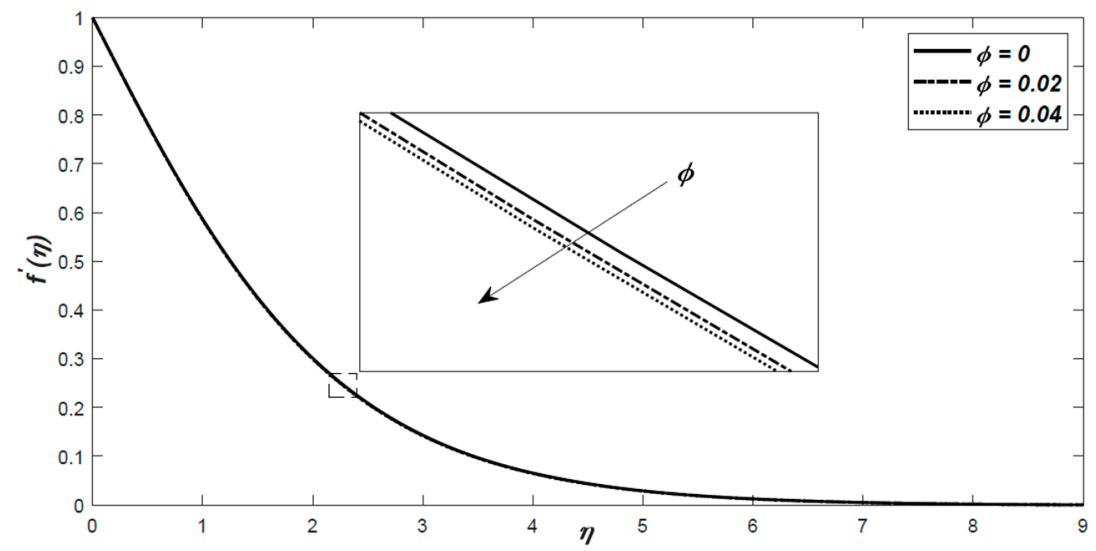

Figure 3. The dimensionless velocity profiles with $\phi$ for $\mathrm{Al}_{2} \mathrm{O}_{3}$-water with respect to similarity variable $\eta$.

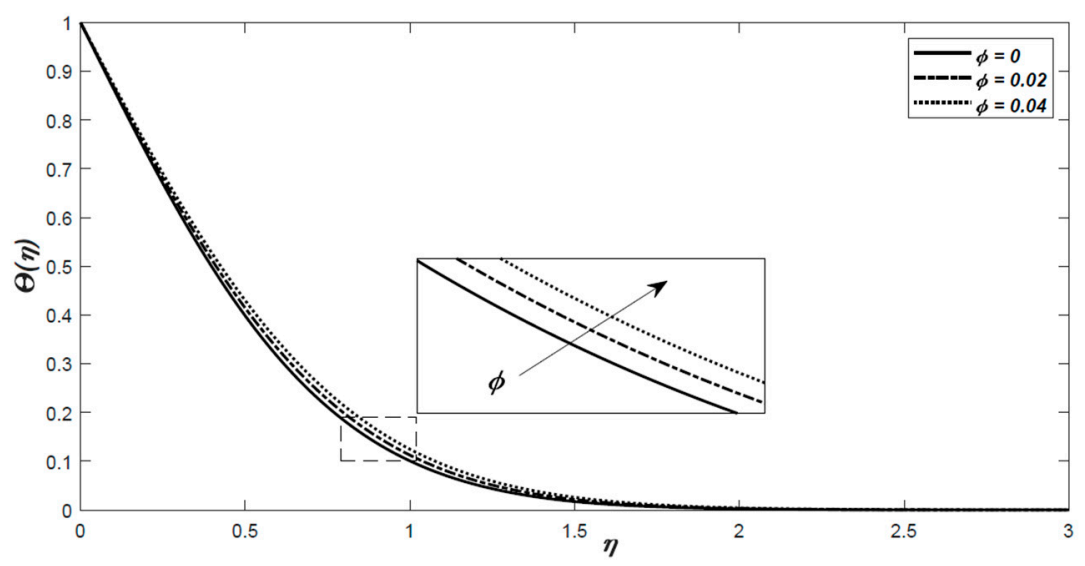

Figure 4. The variation of the dimensionless temperature profiles with $\phi$ for $\mathrm{Al}_{2} \mathrm{O}_{3}$-water with respect to similarity variable $\eta$. 
The skin friction coefficient and the local Nusselt number is of engineering interest, and these will be presented and discussed in detail. The wall shear stress $\left(\tau_{w}\right)$ and heat flux $\left(q_{w}\right)$ are defined as

$$
\tau_{w}=\mu_{n f}\left(\frac{\partial u}{\partial y}\right)_{y=0}, q_{w}=-k_{n f}\left(\frac{\partial T}{\partial y}\right)_{y=0}
$$

while the skin friction coefficient $\left(C_{f}\right)$ and the local Nusselt number $(N u)$ are defined as

$$
C_{f}=\frac{\tau_{w}}{\rho_{b} U^{2}}, \quad N u=\frac{x q_{w}}{k_{n f}\left(T_{w}-T_{n f}\right)} .
$$

Applying the similarity variables defined in (8) and (9), one gets

$$
R e_{x}^{1 / 2} C_{f}=\frac{1}{(1-\phi)^{2.5}} f^{\prime \prime}(0), R e_{x}^{-1 / 2} N u=-\frac{k_{n f}}{k_{b}} \theta^{\prime}(0),
$$

where the local Reynolds number $R e_{x}$ is defined by $\operatorname{Re}_{x}=\frac{\rho_{n f} U x}{\mu_{n f}}$.

\section{Results with CFD Simulations and Discussion}

Nowadays, the computation fluid dynamics (CFD) simulation has become an effective tool to predict results in fluid flow characteristics.

The CFD simulations have been performed for the laminar nanofluid flow, according to Figure 5, and Equations (1)-(3) were discretized and solved using ANSYS 18. The sheet was maintained at a constant temperature $T_{w}=400 \mathrm{~K}$. The fluid flows with constant velocity $U=0.01 \mathrm{~m} / \mathrm{s}$ and the temperature outside the thermal boundary layer was $T_{\infty}=300 \mathrm{~K}$. The length of the plate was $L=1 \mathrm{~m}$. For the computational domain and mesh, the computational domain geometry was generated using Design Modeler, and the grid was generated using ANSYS Fluent mesh. The CFD domain consists of inlet and outlet, which had been divided by the number of division type with 100 divisions; the behaviour was set to hard, with bias factor 40 , in order to increase the number of subdomains near to the plate and increase the preciseness near the wall. The boundary conditions had been set up as follows: side AD is symmetry, $\mathrm{BC}$ is the wall, $\mathrm{AB}$ is the velocity inlet, and $\mathrm{CD}$ is the outlet. Both AD and BC were divided using the same method, with 200 divisions. A laminar model was used with pressure-velocity coupling. The relaxation factor was 1 for density; body force and energy, the thermophysical properties of nanofluids (including density, thermal conductivity, viscosity, and thermal capacity) were calculated using a single-phase approach. In order to check grid sensitivity, the local Nusselt number was evaluated. A comprehensive mesh sensitivity study had been done to minimize the numerical influences introduced by the size of the meshes. The analysis of the mesh sensitivity had been done for five meshes (with the number of cells being 7000, 9600, 14,400, 20,000, and 26,400), and the Nusselt number on the plate for each mesh had been compared. It was noticed that the Nusselt number for the mesh with 20,000 cells was found to be satisfactory to ensure the accuracy $\left(10^{-6}\right)$ of the solution, as well as the independency of the grid, which was applied in the further simulations.

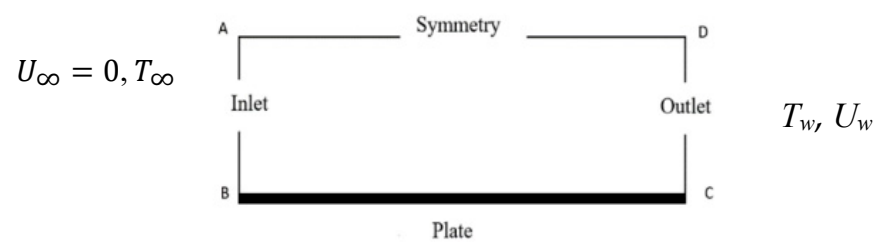

Figure 5. The flow configuration. 
Applying Equations (8)-(11), the effect of volume concentration on the density, viscosity, thermal capacity, and thermal conductivity were determined in [45] for the three nanofluids, with data given in Table 1. It was found that the density and the viscosity increase with $\phi$; however, the thermal capacity and thermal conductivity have opposite behaviour.

Figures 6 and 7 show the impact of the nanoparticles' material on the dimensional velocity and temperature profiles for $\phi=0.02$, respectively. We remark that these figures are in correlation with Figures 1 and 2.

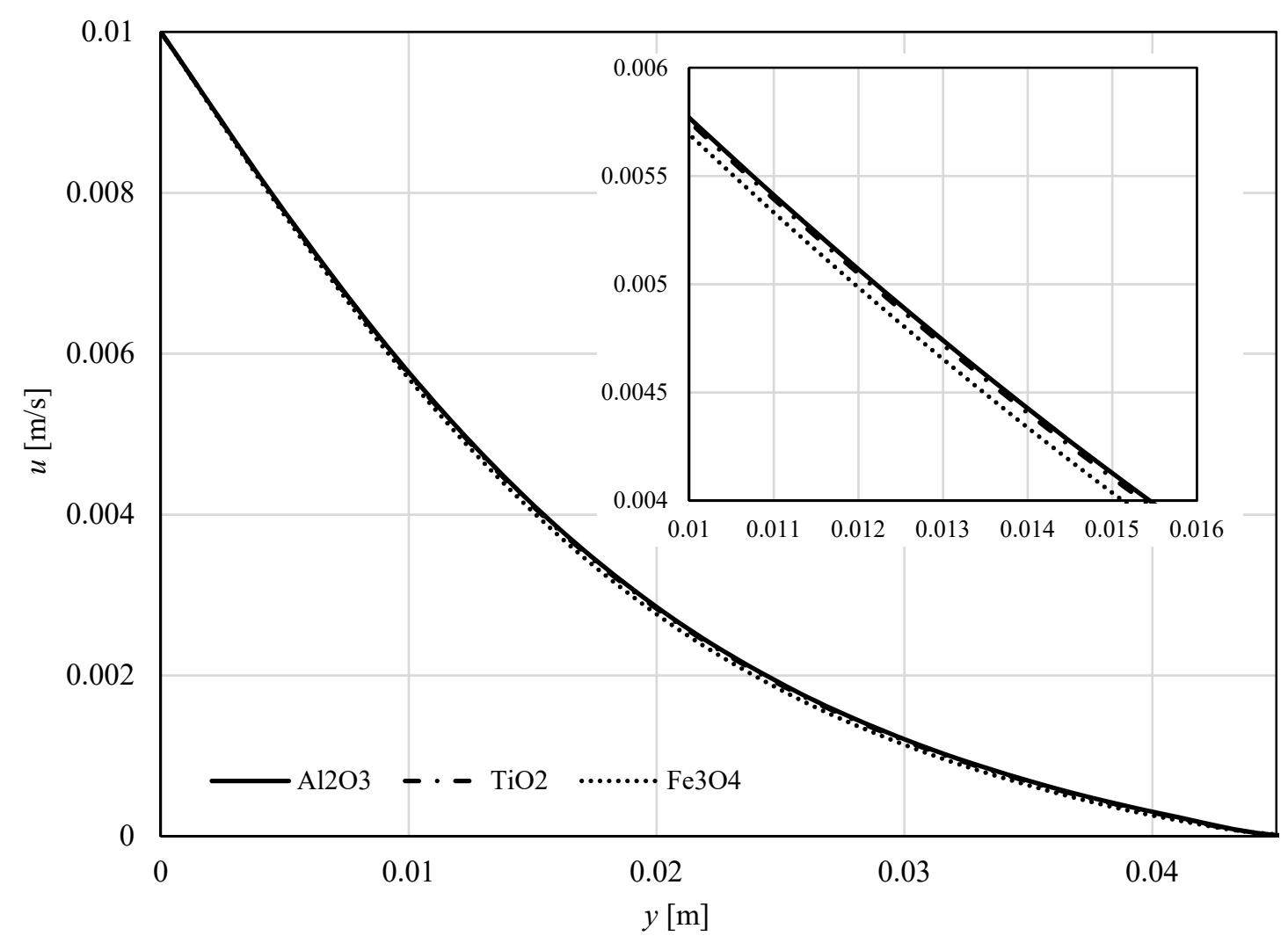

Figure 6. Velocity profiles perpendicular to the sheet for all three nanofluids; $\phi=0.02$.

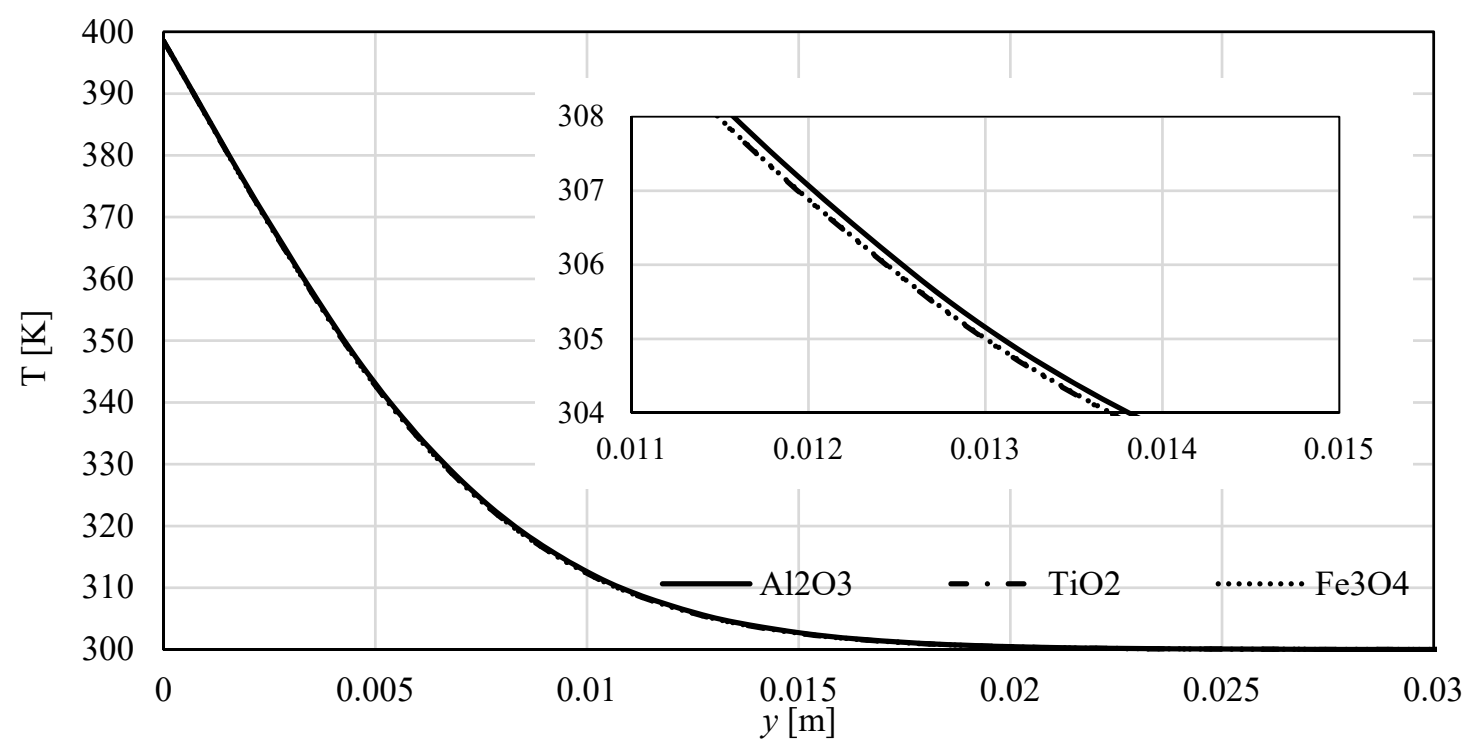

Figure 7. Temperatures profiles perpendicular to the sheet for all three nanofluids; $\phi=0.02$. 
The impact of the nanoparticle's concentration was investigated on $\mathrm{Al}_{2} \mathrm{O}_{3}-$ water nanofluid in Figures 8 and 9. It follows, according to Figures 3 and 4, that more additives will reduce the velocity and increase the velocity.

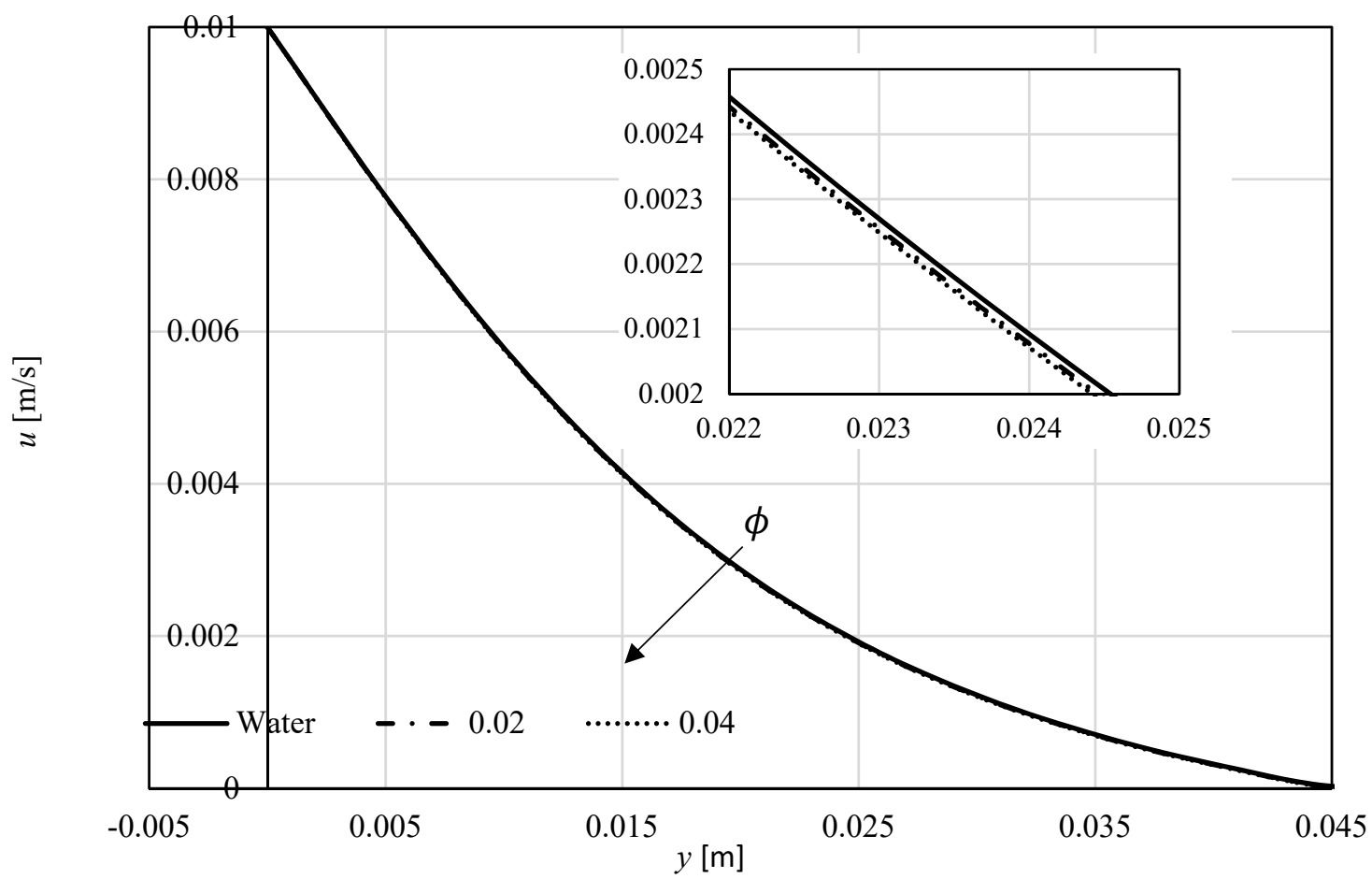

Figure 8. Velocity profiles perpendicularly to the sheet for $\mathrm{Al}_{2} \mathrm{O}_{3}$-water at different volume fractions $\phi$.

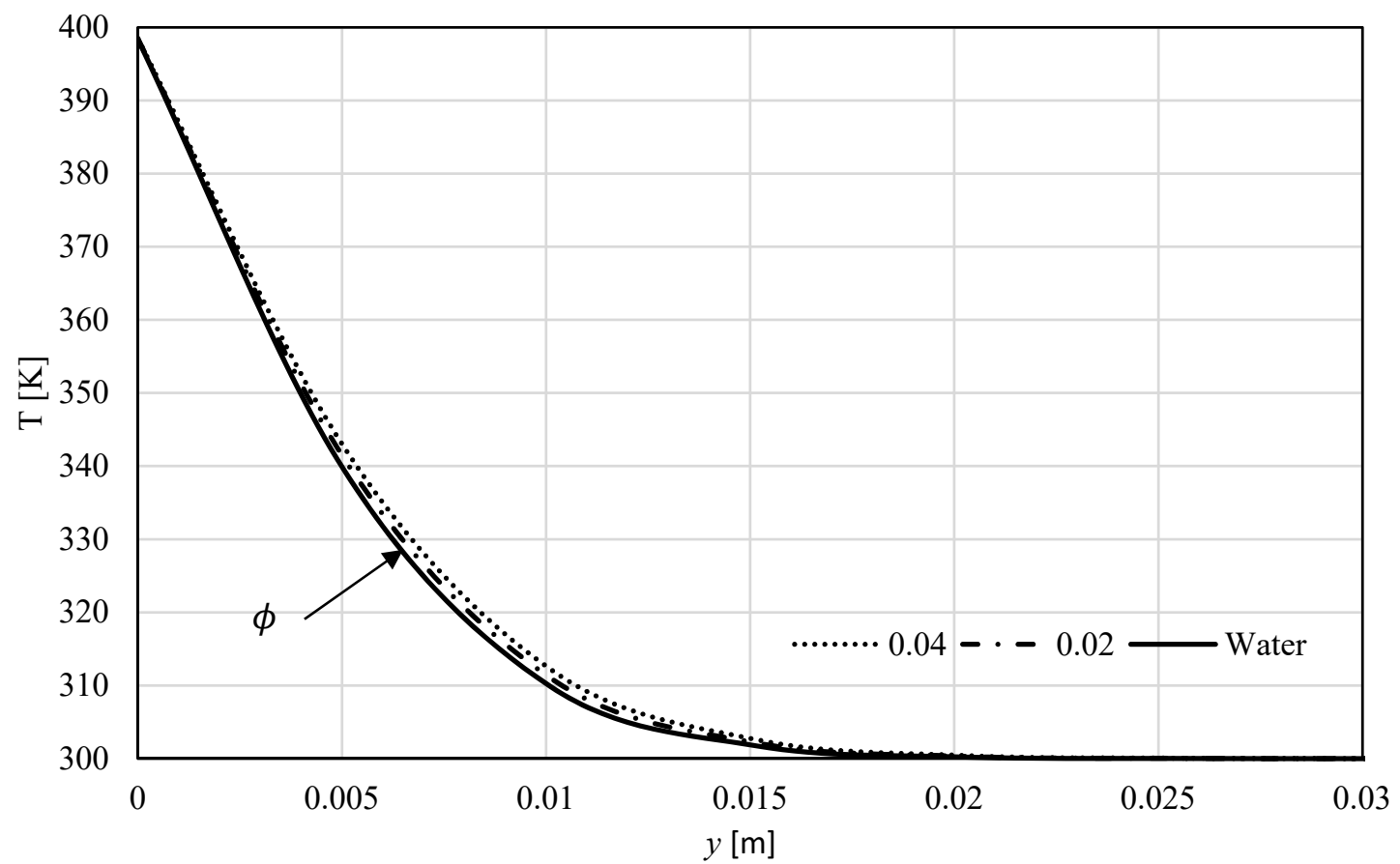

Figure 9. Temperatures profiles perpendicular to the sheet for $\mathrm{Al}_{2} \mathrm{O}_{3}$-water nanofluid at different volume fractions $\phi$.

The skin friction coefficient and the local Nusselt number were analysed using CFD simulations. Figure 10 exhibits the impact of the nanoparticle's material on $C_{f}$ for $\phi=0.02$ along the flat surface. We found that the skin friction is higher $\mathrm{Fe}_{3} \mathrm{O}_{4}$ than for $\mathrm{Al}_{2} \mathrm{O}_{3}$ and $\mathrm{TiO}_{2}$. 


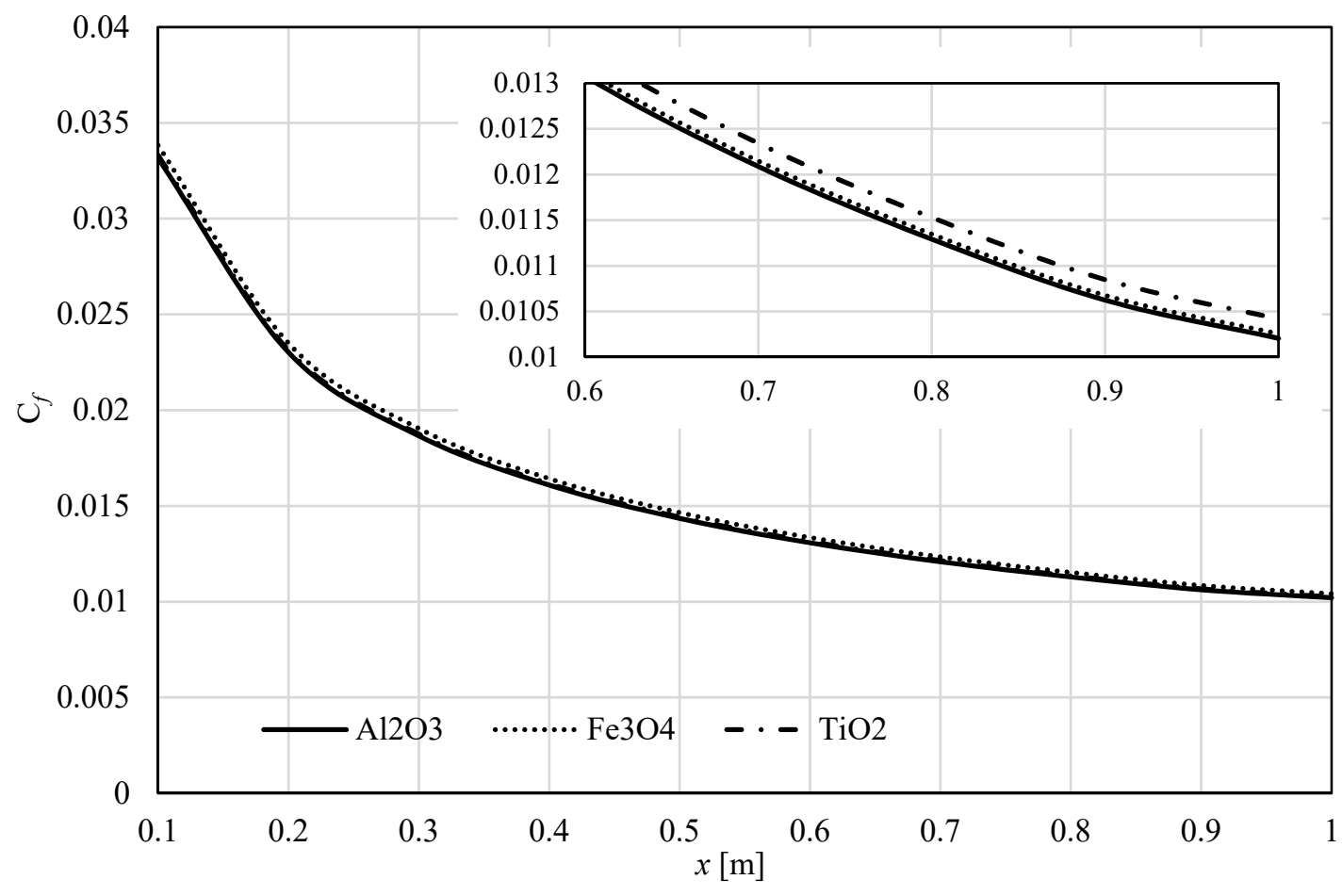

Figure 10. The skin friction $\left(C_{f}\right)$ along the sheet for all three nanofluids $(\phi=0.04)$.

The skin friction coefficient variation with the Reynolds number is shown in Figure 11 for $\mathrm{Al}_{2} \mathrm{O}_{3}$ in the range of the corresponding Reynolds number. We can observe that the larger $\phi$ is, the larger $C_{f}$ is.

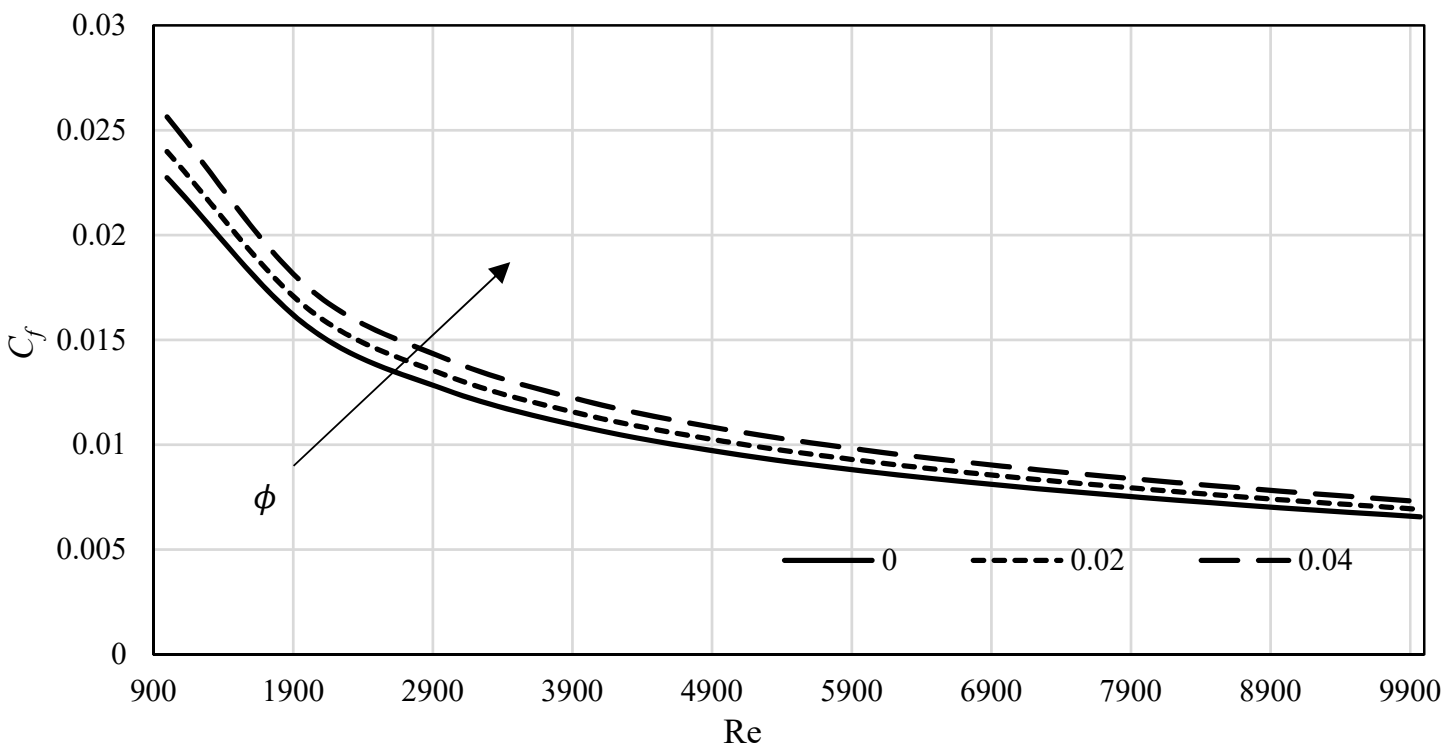

Figure 11. $C_{f}$ versus the Reynolds number at different volume fractions $\phi\left(\mathrm{Al}_{2} \mathrm{O}_{3}\right)$.

The effect of the nanoparticle's material on skin friction is examined in Figure 12, in the range 0.00-0.04. It was concluded that the highest values were obtained for $\mathrm{Fe}_{3} \mathrm{O}_{4}$, while the lowest were for $\mathrm{Al}_{2} \mathrm{O}_{3}$. 


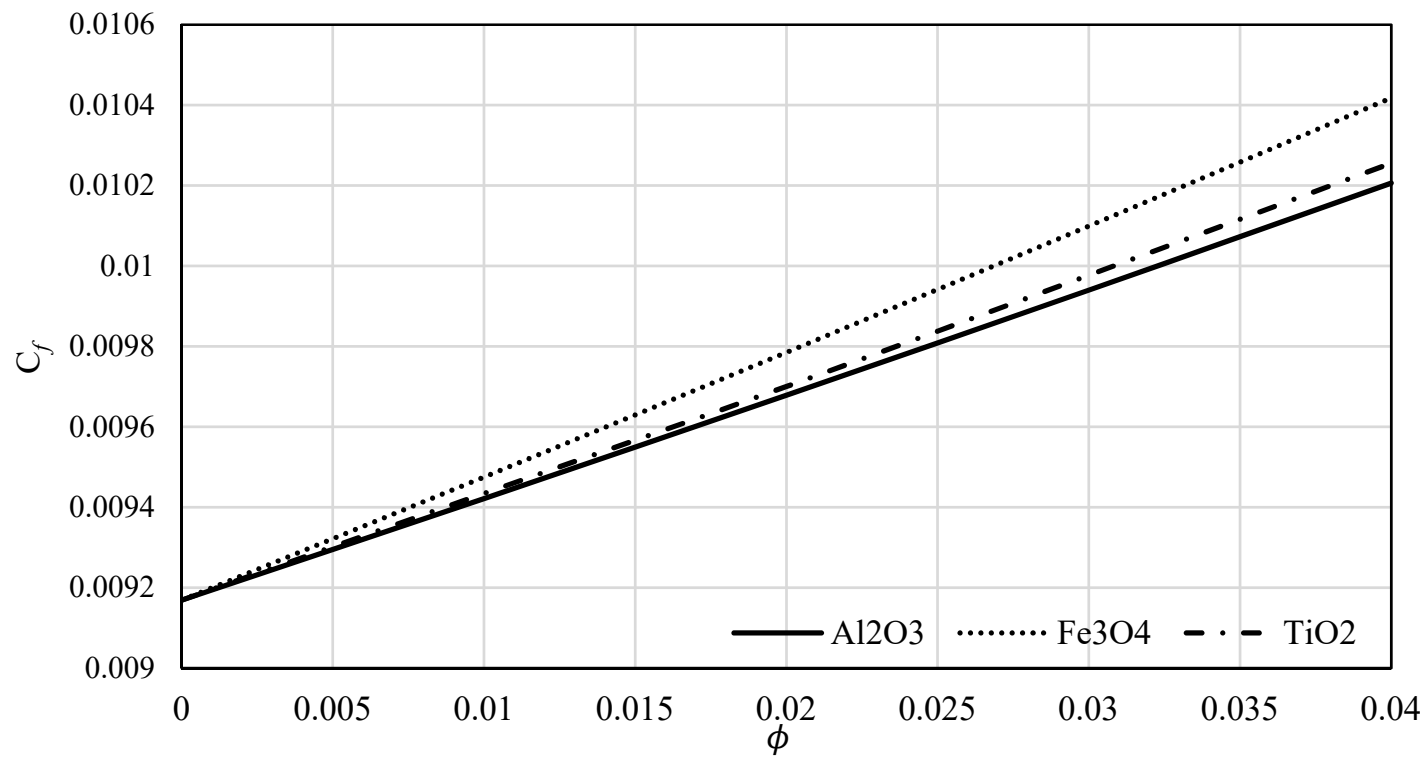

Figure 12. The skin friction $C_{f}$ versus $\phi$ for all three nanofluids.

In Figure 13, the values of $\operatorname{Re}_{x}^{1 / 2} C_{f}$ versus $\phi$ are exhibited for all three additive materials. We remark that the same trends can be seen as in Figure 12.

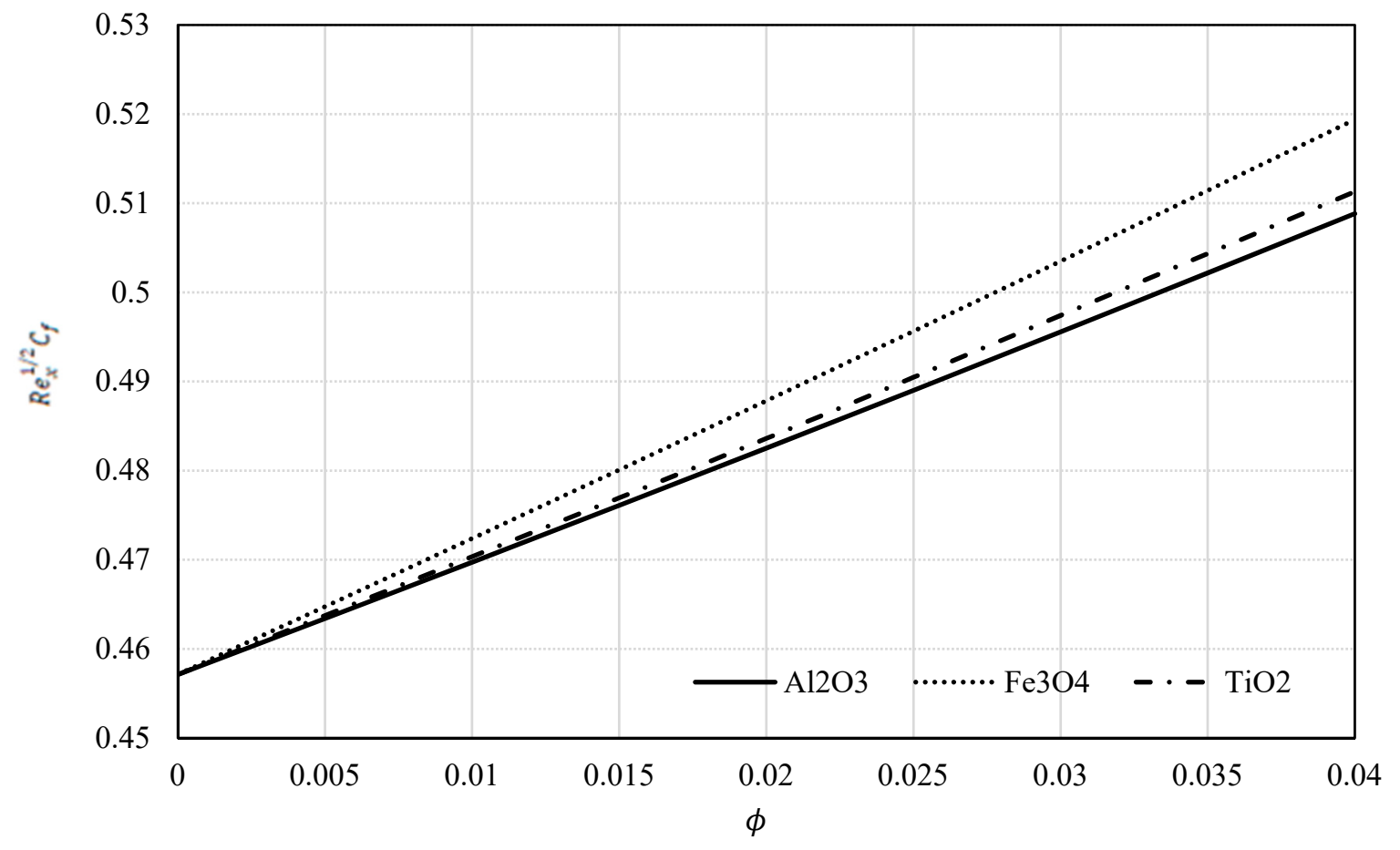

Figure 13. $\operatorname{Re}_{x}^{1 / 2} C_{f}$ versus $\phi$ for all three nanofluids.

Figure 14 depicts the variation of the Nusselt number along the sheet surface. One can see a slight difference along the $x$-axis for all three nanofluids when $\phi=0.02$. The bigger values for $N u$ were obtained for $\mathrm{Al}_{2} \mathrm{O}_{3}$. 


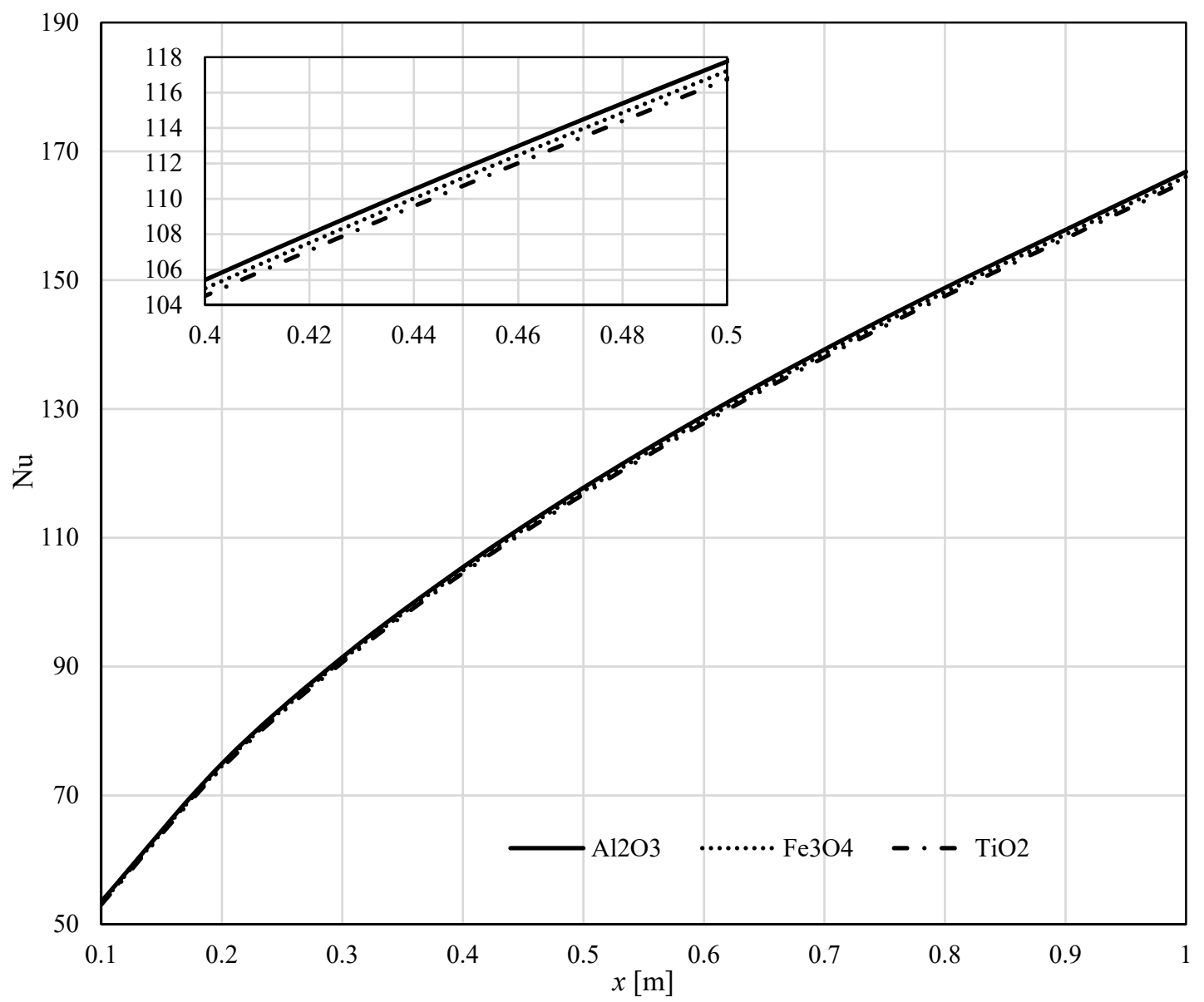

Figure 14. The variation of the Nusselt number for all three nanofluids.

The influence of the volume fraction on the local Nusselt number is investigated in Figure 15 for $\mathrm{Al}_{2} \mathrm{O}_{3}$ in the range of Reynolds number 900-9000. It can be seen from the figure that the increase in $\phi$ will induce an increase in the Nusselt number as well.

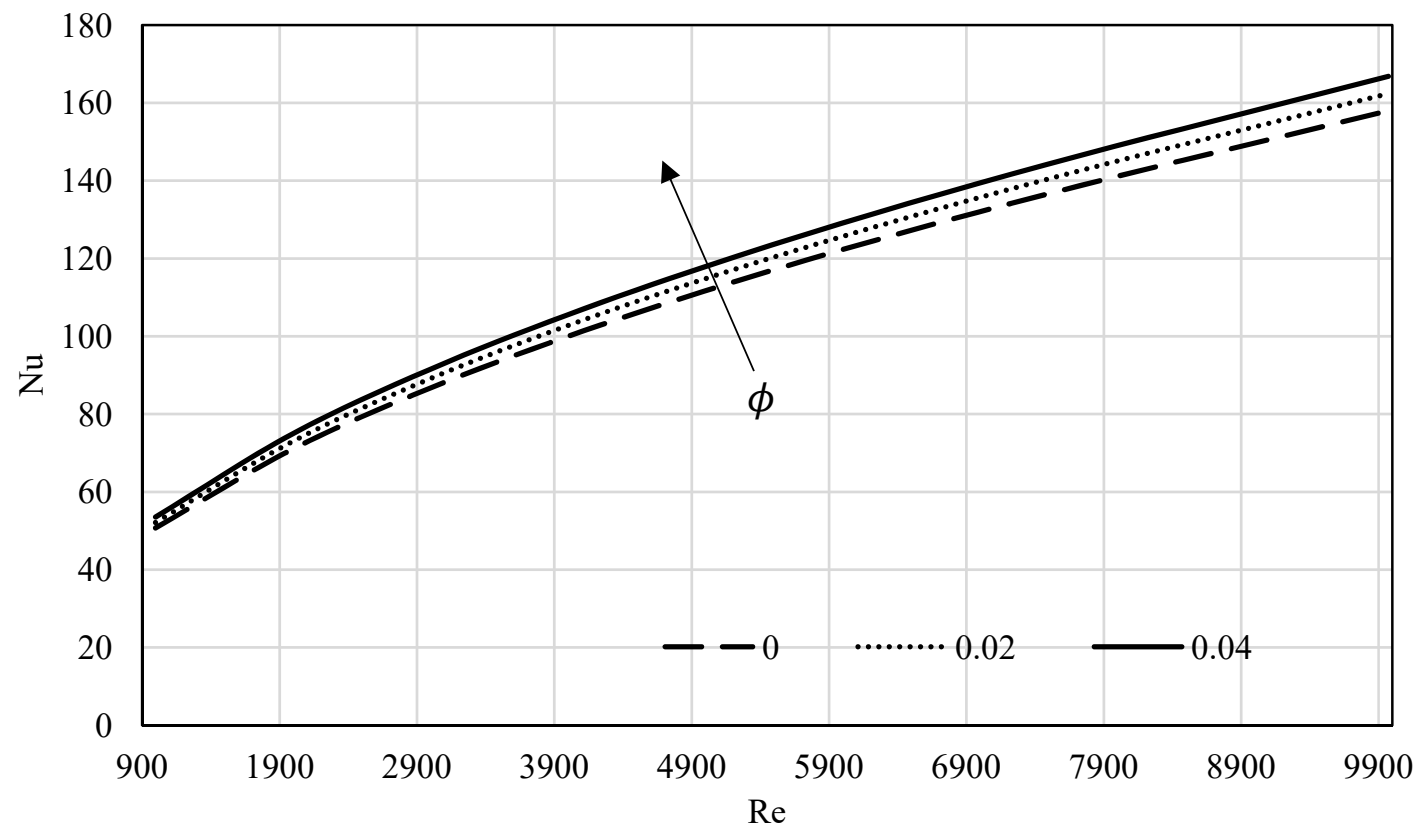

Figure 15. Variation of Nusselt number versus the Reynolds number $(R e)$ for $\mathrm{Al}_{2} \mathrm{O}_{3}$-water. 
In Figure 16, the effect of the nanomaterial on the local Nusselt number is investigated. As the volume fraction increases, the local number of Nusselt number increases. However, the biggest values are obtained for $\mathrm{Al}_{2} \mathrm{O}_{3}$.

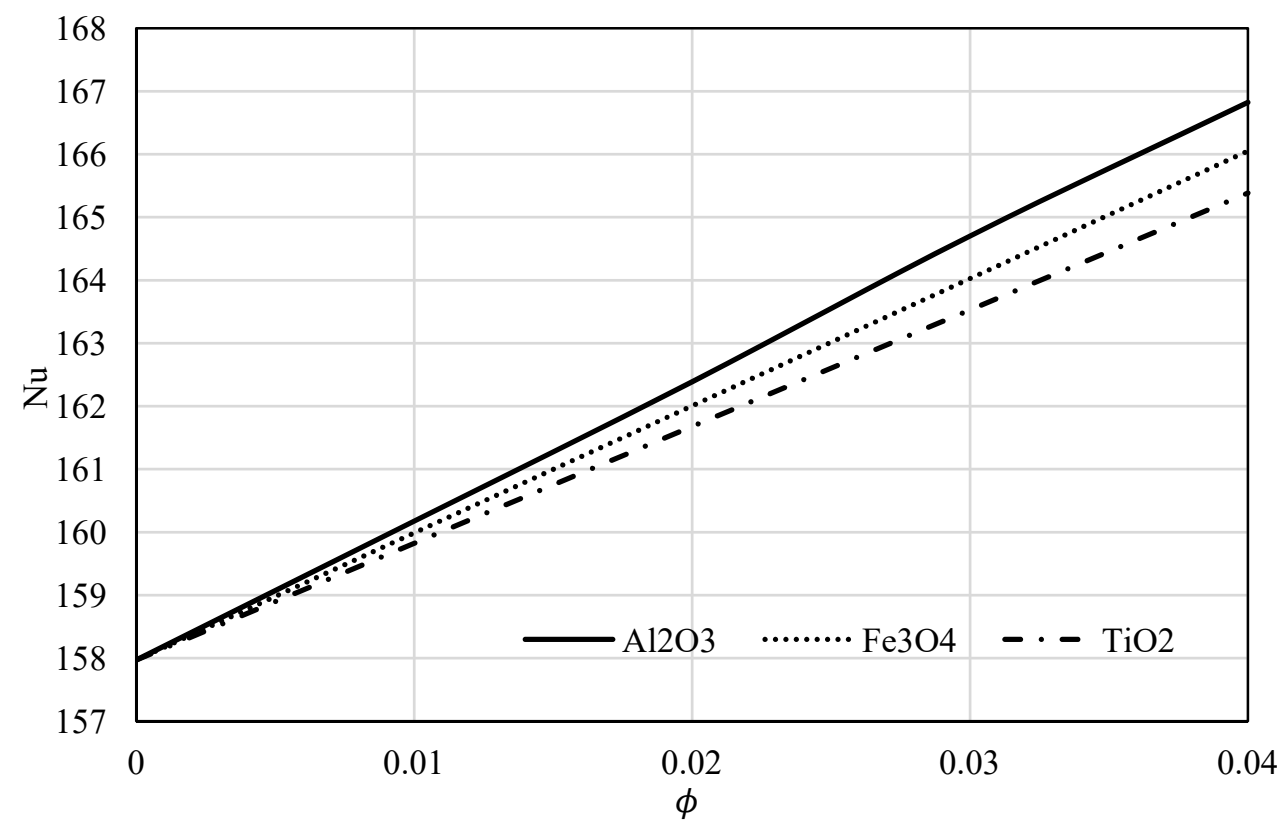

Figure 16. Variation of Nusselt number versus $\phi$ for all three nanofluids.

Figure 17 reveals the impact of the nanoparticle's material on $R e_{x}^{-1 / 2} N u$. We can observe the same trends in Figure 17 as in Figure 16.

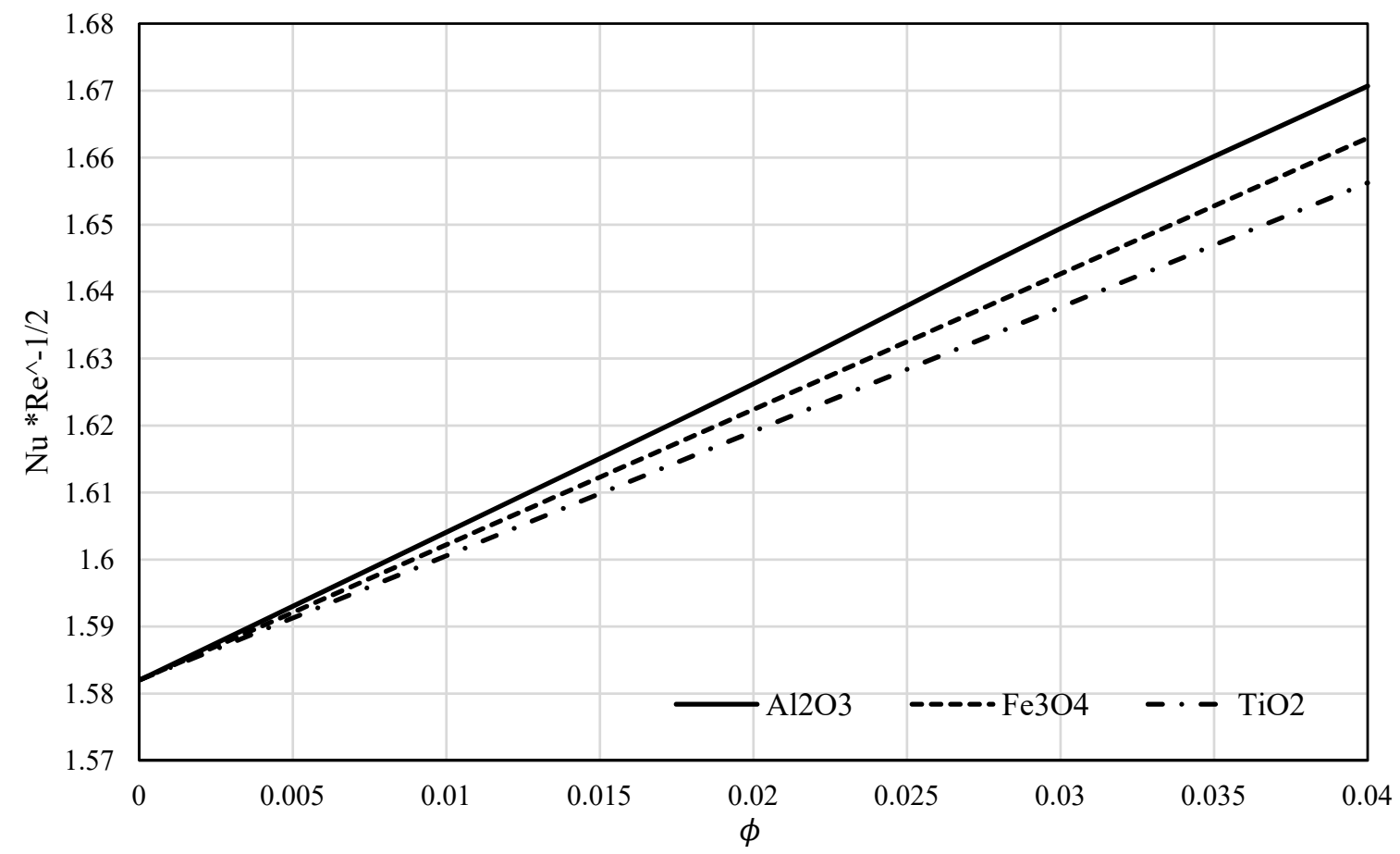

Figure 17. $R e_{x}^{-1 / 2} N u$ versus $\phi$ for all three nanofluids.

Tables 2 and 3 show the comparison of $\operatorname{Re}_{x}^{1 / 2} C_{f}$ and $R e_{x}^{-1 / 2} N u$, respectively. These values are determined by the similarity solutions with $f^{\prime \prime}(0)$ and $\theta^{\prime}(0)$, using the equations in (24) and with 
CFD simulations as well. We remark that in the range 0.00-0.02 for $\phi$, the values obtained with CFD are slightly greater for both quantities than for the analytical solution obtained with the similarity method. However, the difference is small, less than $14.5 \%$, and is especially small (2.7\%) for $\operatorname{Re}_{x}^{1 / 2} C_{f}$ The difference is due to boundary layer approximations. We consider that the CFD simulation results could be closer to the experimental results.

Table 2. Variation of $R e_{x}^{1 / 2} C_{f}$ with $\phi$.

\begin{tabular}{ccccccc}
\hline \multirow{2}{*}{$\phi$} & \multicolumn{2}{c}{$\mathrm{Al}_{\mathbf{2}} \mathrm{O}_{3}$} & \multicolumn{2}{c}{$\mathrm{TiO}_{\mathbf{2}}$} & \multicolumn{2}{c}{$\mathrm{Fe}_{3} \mathrm{O}_{4}$} \\
\cline { 2 - 7 } & Similarity & CFD & Similarity & CFD & Similarity & CFD \\
\hline 0.00 & 0.44455 & 0.45712 & 0.44455 & 0.45712 & 0.44455 & 0.45712 \\
0.01 & 0.45682 & 0.46971 & 0.45743 & 0.47035 & 0.45947 & 0.47238 \\
0.02 & 0.46929 & 0.48252 & 0.47052 & 0.48361 & 0.47458 & 0.48783 \\
0.03 & 0.48198 & 0.49556 & 0.48382 & 0.49741 & 0.48988 & 0.50349 \\
0.04 & 0.49490 & 0.50883 & 0.49735 & 0.51129 & 0.50540 & 0.51938 \\
\hline
\end{tabular}

Table 3. Variation of $R e_{x}^{-1 / 2} N u$ with $\phi$.

\begin{tabular}{ccccccc}
\hline \multirow{2}{*}{$\phi$} & \multicolumn{2}{c}{$\mathrm{Al}_{\mathbf{2}} \mathbf{O}_{3}$} & \multicolumn{2}{c}{$\mathrm{TiO}_{\mathbf{2}}$} & \multicolumn{2}{c}{$\mathrm{Fe}_{3} \mathbf{O}_{4}$} \\
\cline { 2 - 7 } & Similarity & CFD & Similarity & CFD & Similarity & CFD \\
\hline 0.00 & 1.36704 & 1.58199 & 1.36704 & 1.58199 & 1.36704 & 1.58199 \\
0.01 & 1.38267 & 1.60408 & 1.37974 & 1.60056 & 1.38043 & 1.60221 \\
0.02 & 1.39833 & 1.62624 & 1.39426 & 1.61913 & 1.39387 & 1.62240 \\
0.03 & 1.41401 & 1.64942 & 1.40520 & 1.63766 & 1.40737 & 1.64264 \\
0.04 & 1.42975 & 1.67068 & 1.41798 & 1.65624 & 1.42093 & 1.66293 \\
\hline
\end{tabular}

\section{Conclusions}

The Sakiadis flow was investigated by determining the velocity and temperature in three types of nanofluids along a continuously moving sheet surface. The skin friction coefficient and the local Nusselt number were calculated. Two methods were used: one of them was analytically applying the traditional Blasius' similarity transformation, and solving the obtained coupled ordinary differential equations; the other solution was obtained using CFD simulations. We found that the solid volume fraction significantly influences the fluid flow and heat transfer properties. Comparing the three nanoparticles' materials, we note that the $\mathrm{Al}_{2} \mathrm{O}_{3}$ has significantly greater thermal conductivity. The larger velocity and temperature values are obtained in the boundary layer for alumina-water fluid than for the other two nanomaterials. Increasing the concentration of nanomaterial has produced a decrease in velocity and an increase in temperature in the momentum and thermal boundary layers, respectively. The skin friction decreases and the Nusselt number increases with the Reynolds number. The values of $C_{f}$ and $\mathrm{Nu}$ are depicted with the nanoparticle concentration. It was concluded that both linearly increase with $\phi$ (see Figures 12 and 16). For $\mathrm{Al}_{2} \mathrm{O}_{3}$, the values of the skin friction coefficient are smaller than for titania $\left(\mathrm{TiO}_{2}\right)$ and magnetite $\left(\mathrm{Fe}_{3} \mathrm{O}_{4}\right)$; conversely, the Nusselt number values are greater than those for the other two materials. It was found that the type of nanofluid is a key factor in improving heat transfer. The behaviour of the skin friction coefficient and the local Nusselt number is like that described by Ahmad et al. [31] and Bachok et al. [32]. The simulation results obtained by CFD gave slightly bigger values for $R e_{x}^{1 / 2} C_{f}$ and $R e_{x}^{-1 / 2} N u$, which indicates that the skin friction should be slightly higher in reality than the value calculated, according to boundary layer theory.

Author Contributions: G.B.: conceptualization, methodology, investigation, formal analysis, and writing—original draft preparation; M.K.: methodology, investigation, numerical simulation, data curation, and writing-review and editing; K.H.: methodology, investigation, numerical simulation, data curation, and writing-review and editing. All authors have read and agreed to the published version of the manuscript. 
Funding: This work was supported by Project No. 129257 and implemented with support provided from the National Research, Development and Innovation Fund of Hungary, financed under the K_18 funding scheme and GINOP-2.3.4-15-2016-00004 project, which aims to promote cooperation between higher education and industry, is supported by the European Union and the Hungarian State, and is co-financed by the European Regional Development Fund interest.

Conflicts of Interest: The authors declare no conflict of interest.

\section{References}

1. Prandtl, L. Über Flüssigkeitsbewegungen bei sehr kleiner Reibung. In Vier Abhandlungen zur Hydromechanik und Aerodynamik; Prandtl, L., Betz, A., Eds.; Universitatsverlag Göttingen: Göttingen, Germany, 2010; pp. 484-494.

2. Blasius, H. Grenzschichten in Flüssigkeiten mit kleiner Reibung. Z. Angew. Math. Phys. 1909, 56, 1-37.

3. Schlichting, H. Boundary Layer Theory, 8th ed.; Springer: New York, NY, USA, 2020; ISBN 3540662707/978-3540662709.

4. Altan, T.; Oh, S.; Gegel, G. Metal Forming Fundamentals and Applications; ASM International: Cleveland, $\mathrm{OH}$, USA, 1983.

5. Fisher, E.G. Extrusion of Plastics; Wiley: New York, NY, USA, 1976.

6. Tadmor, Z.; Gogos, C. Principles of Polymer Processing; Wiley: New York, NY, USA, 1979.

7. Sakiadis, B.C. Boundary-layer behaviour on continuous solid surfaces: I. Boundary-layer equations for two-dimensional and axisymmetric flow. AIChE J 1961, 7, 26-28. [CrossRef]

8. Tsou, F.; Sparrow, E.; Goldstein, R. Flow and heat transfer in the boundary layer on a continuous moving surface. Int. J. Heat Mass Transf. 1967, 10, 219-235. [CrossRef]

9. Crane, L.J. Flow past stretching plate. Z. Angew. Math. Phys. 1970, 21, 645-647. [CrossRef]

10. Chakrabarti, A.; Gupta, A.S. Hydromagnetic flow and heat transfer over a stretching sheet. Q. Appl. Math. 1979, 37, 73-78. [CrossRef]

11. Banks, W.H.H. Similarity solutions of the boundary layer equations for a stretching wall. JMecT 1983, 2, 375-392.

12. Bognár, G.V. On similarity solutions of boundary layer problems with upstream moving wall in non-Newtonian power-law fluids. IMA J. Appl. Math. 2011, 77, 546-562. [CrossRef]

13. Bognár, G.V.; Csáti, Z. Numerical Solution to Boundary Layer Problems over Moving Flat Plate in Non-Newtonian Media. J. Appl. Math. Phys. 2014, 2, 8-13. [CrossRef]

14. Bognár, G.V. Numerical method for the boundary layer problems of non-Newtonian fluid flows along moving surfaces. Electron. J. Qual. Theory Differ. Equations 2016, 1-11. [CrossRef]

15. Haider, S.; Butt, A.S.S.; Li, Y.-Z.; Imran, S.M.; Ahmad, B.; Tayyaba, A. Study of entropy generation with multi-slip effects in MHD unsteady flow of viscous fluid past an exponentially stretching surface. Symmetry 2020, 12, 426. [CrossRef]

16. Mahabaleshwar, U.S.; Kumar, P.V.; Nagaraju, K.R.; Bognár, G.; Nayakar, S.N.R. A new exact solution for the flow of a fluid through porous media for a variety of boundary conditions. Fluids 2019, 4, 125. [CrossRef]

17. Andersson, H.I. MHD flow of a viscoelastic fluid past a stretching surface. Acta Mech. 1992, 95, $227-230$. [CrossRef]

18. Tonekaboni, S.A.M.; Abkar, R.; Khoeilar, R. On the Study of Viscoelastic Walters' B Fluid in Boundary Layer Flows. Math. Probl. Eng. 2012, 2012, 1-18. [CrossRef]

19. Siddheshwar, P.; Mahabaleshwar, U.; Chan, A. MHD flow of walters' liquid b over a nonlinearly stretching sheet. Int. J. Appl. Mech. Eng. 2015, 20, 589-603. [CrossRef]

20. Singh, J.; Mahabaleshwar, U.S.; Bognar, G. Mass transpiration in nonlinear MHD flow due to porous stretching sheet. Sci. Rep. 2019, 9, 1-15. [CrossRef]

21. Takhar, H.S.; Nitu, S.; Pop, I. Boundary layer flow due to a moving plate: Variable fluid properties. Acta Mech. 1991, 90, 37-42. [CrossRef]

22. Pop, I.; Gorla, R.S.R.; Rashidi, M. The effect of variable viscosity on flow and heat transfer to a continuous moving flat plate. Int. J. Eng. Sci. 1992, 30, 1-6. [CrossRef]

23. Elbashbeshy, E.M.A.; Bazid, M.A.A. The effect of temperature-dependent viscosity on heat transfer over a continuous moving surface. J. Phys. Appl. Phys. 2000, 33, 2716-2721. [CrossRef]

24. Andersson, H.I.; Aarseth, J.B. Sakiadis flow with variable fluid properties revisited. Int. J. Eng. Sci. 2007, 45, 554-561. [CrossRef] 
25. Choi, S.U.S. Enhancing thermal conductivity of fluids with nanoparticles. In Proceedings of the 1995 ASME International Mechanical Engineering. Congress and Exposition, San Francisco, CA, USA, 12-17 November 1995; pp. 99-105.

26. Das, S.K.; Choi, S.U.S.; Yu, W.; Pradet, T. Nanofluids: Science and Technology; Wiley: Hoboken, NJ, USA, 2007.

27. Xuan, Y.; Li, Q. Heat transfer enhancement of nanofluids. Int. J. Heat Fluid Flow 2000, 21, 58-64. [CrossRef]

28. Wong, K.V.; De Leon, O. Applications of nanofluids: Current and future. Adv. Mech. Eng. 2010, $2,519659$. [CrossRef]

29. Raza, J.; Mebarek-Oudina, F.; Mahanthesh, B. Magnetohydrodynamic flow of nano Williamson fluid generated by stretching plate with multiple slips. Multidiscip. Model. Mater. Struct. 2019, 15, 871-894. [CrossRef]

30. Ibrahim, W. Magnetohydrodynamic (MHD) boundary layer stagnation point flow and heat transfer of a nanofluid past a stretching sheet with melting. Propuls. Power Res. 2017, 6, 214-222. [CrossRef]

31. Ahmad, S.; Rohni, A.M.; Pop, I. Blasius and Sakiadis problems in nanofluids. Acta Mech. 2010, 218, $195-204$. [CrossRef]

32. Bachok, N.; Ishak, A.; Pop, I. Flow and heat transfer characteristics on a moving plate in a nanofluid. Int. J. Heat Mass Transf. 2012, 55, 642-648. [CrossRef]

33. Gingold, H. Modelling fluid flow over solid surfaces. Int. J. Model. Identif. Control. 2014, 21, 237. [CrossRef]

34. Liepmann, H.W. Investigations on Laminar Boundary-Layer Stability and Transition on Curved Boundaries; NACA Wartime Report; National Advisory Committee for Aeronautics: Washington, DC, USA, May 1946.

35. Janour, Z. Resistance of a Plate in Parallel Flow at Low Reynolds Number; NACA Technical Memorandum; National Advisory Committee for Aeronautics: Washington, DC, USA, November 1953.

36. Schaaf, S.A.; Sherman, F.S. Skin Friction in Slip Flow. J. Aeronaut. Sci. 1954, 21, 85-90. [CrossRef]

37. Farniya, A.A.; Esplandiu, M.J.; Bachtold, A. Sequential Tasks Performed by Catalytic Pumps for Colloidal Crystallization. Langmuir 2014, 30, 11841-11845. [CrossRef]

38. Niu, R.; Palberg, T. Seedless assembly of colloidal crystals by inverted micro-fluidic pumping. Soft Matter 2018, 14, 3435-3442. [CrossRef]

39. Kudenatti, R.B.; Misbah, N.-E. Hydrodynamic flow of non-Newtonian power-law fluid past a moving wedge or a stretching sheet: A unified computational approach. Sci. Rep. 2020, 10, 9445. [CrossRef]

40. Rasool, G.; Shafiq, A.; Khalique, C.M.; Zhang, T. Magnetohydrodynamic Darcy-Forchheimer nanofluid flow over a nonlinear stretching sheet. Phys. Scr. 2019, 94, 105221. [CrossRef]

41. Dero, S.; Rohni, A.M.; Saaban, A. MHD micropolar nanofluid flow over an exponentially stretching/shrinking surface: Triple solutions. J. Adv. Res. Fluid Mech. Therm. Sci. 2019, 56, 165-174.

42. Khan, S.A.; Nie, Y.; Ali, B. Multiple Slip Effects on Magnetohydrodynamic Axisymmetric Buoyant Nanofluid Flow above a Stretching Sheet with Radiation and Chemical Reaction. Symmetry 2019, 11, 1171. [CrossRef]

43. Ali, B.; Nie, Y.; Khan, S.A.; Sadiq, M.T.; Tariq, M. Finite Element Simulation of Multiple Slip Effects on MHD Unsteady Maxwell Nanofluid Flow over a Permeable Stretching Sheet with Radiation and Thermo-Diffusion in the Presence of Chemical Reaction. Processes 2019, 7, 628. [CrossRef]

44. Oztop, H.F.; Abu-Nada, E. Numerical study of natural convection in partially heated rectangular enclosures filled with nanofluids. Int. J. Heat Fluid Flow 2008, 29, 1326-1336. [CrossRef]

45. Klazly, M.; Bognár, G. CFD study for the flow behaviour of nanofluid flow over flat plate. Int. J. Mech. 2020, $14,49-57$.

(C) 2020 by the authors. Licensee MDPI, Basel, Switzerland. This article is an open access article distributed under the terms and conditions of the Creative Commons Attribution (CC BY) license (http://creativecommons.org/licenses/by/4.0/). 